\title{
DOMÁCIAS E ÁCAROS EM CAFEEIROS
}

\author{
Jeferson Luiz de Carvalho Mineiro*, Mário Eidi Sato \& Adalton Raga \\ Instituto Biológico/APTA, Centro Avançado de Pesquisa em Proteção de Plantas e Saúde Animal. \\ Alameda dos Vidoeiros, n 1097. CEP 13101-680. Gramado, Campinas, São Paulo, Brasil. \\ *E-mail: jefmin@hotmail.com
}

\begin{abstract}
Resumo
Domácia é de origem grega "domatium" e que significa casa pequena. Essas estruturas foram interpretadas como "adaptações a uma simbiose mutualística entre a planta e os ácaros que ali vivem", mas esta teoria foi logo abandonada pelos botânicos, que passaram a utilizar o termo domácia apenas para as estruturas presentes nas junções das nervuras das folhas. Pouco se conhece a respeito da função das domácias em cafeeiro. As domácias podem servir de refúgio para os ácaros às condições fisiologicamente estressantes na superfície da folha ou aos inimigos naturais. $O$ orifício e a câmara da domácia podem variar em função dos aspectos nutricionais, ou seja, plantas que apresentam deficiências nutricionais podem provocar essas alterações na domácia. A temperatura e a precipitação parecem estar correlacionadas com o número de domácias. Estes fatores combinados a fatores nutricionais da planta poderiam afetar diferentes aspectos das domácias e influenciar a comunidade de ácaros presentes nestas estruturas.
\end{abstract}

Palavras-chaves: Phytoseiidae, Stigmaeidae, Coffea arabica, Coffea canephora 


\section{Abstract}

\section{LEAF DOMATIA AND MITES IN COFFEE PLANTS.}

Leaf domatia is of Greek origin "domatium" and it means small house. These structures were interpreted as "adaptations to a mutualistic symbiosis between the plant and the mites that living there", but this theory was soon abandoned by botanists, who came to use the term leaf domatia only for the structures present in the junctions of leaf veins. Little is known about the function of coffee domatia. Leaf domatia can provide shelter for mites to physiologically stressful conditions on the leaf surface or to natural enemies. The orifice and chamber of the domatia may vary according to the nutritional aspects, that is, plants that present nutritional deficiencies can cause these changes in the domatia. Temperature and precipitation seem to be correlated with the number of domains. These factors combined with nutritional factors of the plant could affect different aspects of the domatia and influence the community of mites present in these structures.

Key words: Phytoseiidae, Stigmaeidae, Coffea arabica, Coffea canephora

Domácias são estruturas presentes nas folhas de diversas espécies de plantas, sendo encontradas sob a forma de tufos de pelos ou cavidades (com ou sem pelos) localizadas nas junções entre a nervura principal e as secundárias, na face abaxial das folhas. Em geral, a distribuição de domácias ocorre desde a base do limbo até aproximadamente 2/3 do comprimento da folha. Além disso, o número e a forma, dessas estruturas variam em nível intra e interespecífico (ADÂMOLI DE BARROS, 1961; GERSON et al., 2003).

O termo domácia foi utilizado pela primeira vez por LUNDSTRÖEM (1887) que, após estudar essa estrutura, observou que a mesma servia de refúgio e moradia para ácaros, dando-lhe essa denominação. Domácia é de origem gre- ga "domatium" e que significa casa pequena. Essas estruturas foram interpretadas como "adaptações a uma simbiose mutualística entre a planta e os ácaros que ali vivem", mas esta teoria foi logo abandonada pelos botânicos, que passaram a utilizar o termo domácia apenas para as estruturas presentes nas junções das nervuras das folhas. As primeiras observações sobre domácias, no Brasil, foram feitas por GÖLDI (1892) em folhas de cafeeiro, que as descreveu como pequenas saliências do tamanho de uma cabeça de alfinete, presentes em todos os pontos das ramificações das nervuras secundárias nas folhas.

Ao longo dos anos, as domácias tornaram-se objeto de estudos mais detalhados atribuindo-lhes valor morfológico e taxonômico (CHEVALIER, 1947; 
ADÂMOLI DE BARROS, 1961; WRIGLEY, 1988). Contudo, durante muito tempo, as relações entre essas estruturas e a presença de ácaros foram ignoradas (O'DOWD; WILSON, 1989; MATOS et al., 2006).

Pouco se conhece a respeito da função das domácias em cafeeiros. A seguir, descrevemos informações disponíveis na literatura sobre domácias no gênero Coffea e novos detalhes anotados pelos autores do presente trabalho.

\section{Domácias em Coffea arabica L.}

As domácias podem servir de refúgio para os ácaros às condições fisiologicamente estressantes na superfície da foIha (GROSTAL; O'DOWD, 1994) ou ao abrigo de inimigos naturais (PEMBERTON; TURNER, 1989).

Em C. arabica, em particular, as domácias possuem câmara globular com orifício de vários formatos e diâmetros, variando de arredondados a alongados (Figura 1). As bordas dos orifícios das domácias apresentaram-se geralmente glabras BITANCOURT (1927), CHEVALIER (1947), DEDECCA (1957), ADÂMOLI DE BARROS (1961), WRIGLEY (1988), NAKAMURA et al., 1992, O'DOWD (1994) e MINEIRO (2006).

Segundo BITANCOURT (1927), nem todas as domácias são ocupadas por ácaros. Dentre os fatores que poderiam interferir na ocupação das domácias, estariam o diâmetro e formato do orifício, bem como o tamanho da câmara. Outro fator que afetaria a presença ou ausência de ácaros nas domácias seria o aspec- to nutricional da planta, ou seja, plantas que apresentam deficiências nutricionais podem provocar essas alterações na domácia (ADÂMOLI DE BARROS, 1963). A temperatura e a precipitação parecem estar correlacionadas com o número de domácias. Esses fatores combinados poderiam afetar diferentes aspectos das domácias e influenciar a comunidade de ácaros presentes nestas estruturas.

Desde a década de 1990, Instituto Biológico tem avaliado as domácias de diferentes cultivares de cafeeiro nas condições do Estado de São Paulo. As cultivares Mundo Novo, Icatu Vermelho, Icatu Amarelo e Catuaí Amarelo foram as mais estudadas, as quais possuem câmara globular, com orifícios de vários formatos e diâmetros, variando de arredondado a alongado. Na Tabela 1, são quantificadas as domácias de diferentes cultivares de cafeeiro.

\section{Domácias em Coffea canephora cv.}

\section{Apoatã}

As domácias encontradas nessa cultivar foram particularmente diferentes em relação àquelas de $C$. arabica. Essas se assemelham a cavidades pouco profundas, com pelos junto às bordas. Em algumas folhas que não apresentaram domácias, foram observados apenas tufos de pelos (Figura 2). Apesar do tamanho dessa folha ser maior em relação às de arábica, que podem chegar a $30 \mathrm{~cm}, 0$ número médio de domácias observado foi inferior às cultivares de café de arábica (Tabela 1). 
Em relação às domácias da cultivar Apoatã há poucas informações quanto ao formato, tamanho, presença ou ausência (MINEIRO et al., 2006b). Neste trabalho pode-se constatar que as domácias na cultivar Apoatã apresentam forma distinta à de café arábica e uma alta variação quanto ao número de domácias por folha.

Algumas das variedades de café Robusta podem não apresentar domácias, algumas raras com três domácias por foIha, outras com domácias muito pequenas, outras com tufos de pelos ou ainda uma combinação de pequenas domácias e tufos de pelos (CHEVALIER, 1947).

\section{Domácias em Coffea racemosa} Lour.

Geralmente as folhas não apresentam domácias ou quando possuem, são poucas. Apresentam formato de cavidade e possuem pelos (Figura 3 ) e estão situadas junto à nervura central e secundária.

\section{Domácias em Coffea salvatrix} Swynn. \& Philipson

Apresentam formato de cavidade, possuem pelos e estão situadas junto à nervura central e secundária (Figura 4).

\section{Domácias em Coffea stenophylla G. Don}

São em formato de cavidade e glabras. Estão situadas junto à nervura central e secundária (Figura 5).

\section{Domácias em Coffea canephora cv. Guarini}

Apresentam formato de cavidade e possuem glabras. Estão situadas junto à nervura central e na nervura secundária (Figura 6). Até o presente momento, não há estudos sobre os ácaros presentes no interior dessas domácias e fauna de ácaros nessa cultivar.

\section{VII. Ácaros}

O cafeeiro assim como outras plantas possuem estruturas morfológicas conhecidas como domácias ou acarodomácia, que fornece abrigo e/ou alimento a diversas espécies de artrópodes predadores, muitos dos quais atuam no controle de pragas (WALTER, 1996; WALTER; PROCTOR, 1999; GERSON et al., 2003; MATOS et al., 2006; HOY, 2011; GERSON, 2014). A grande maioria dos artrópodes que são encontrados no interior das domácias são ácaros (O'DOWD, 1994; MINEIRO et al., 2006a, 2006b, 2008; REIS; ZACARIAS, 2007). Dentre as espécies mais comumente encontradas, estão as de predadores de outros ácaros (Phytoseiidae e Stigmaeidae) ou espécies de hábitos alimentares (MINEIRO et al., 2006a, 2006b; REIS; ZACARIAS, 2007) variados que utilizam estas estruturas como abrigo e refúgio contra seus inimigos (Tabela 2). Ocasionalmente, ácaros fitófagos também são encontrados no interior das domácias (PEMBERTON; TURNER, 1989; O'DOWD, 1994; GROSTAL; O'DOWD, 1994; ROZARIO, 1995; MCMURTRY; CROFT, 1997; GER- 
SON et al., 2003; ROMERO; BENSON, 2005; MINEIRO et al., 2006a, 2006b, 2008; VEGA et al., 2007), assim como pequenos insetos (RAGA et al., 2003), mas raramente são vistos em abundância.

Diversos estudos têm sido recentemente conduzidos sobre as interações entre ácaros predadores e domácias (PEMBERTON; TURNER, 1989; AGRAWAL; KARBAN, 1997; NORTON et al., 2000; GERSON et al., 2003; MATOS et al., 2004; ROMERO; BENSON, 2005, MINEIRO et al., 2006a, 2006b, 2008; ROMERO et al., 2011). As domácias vêm sendo alvo de diversos estudos com o objetivo de comprovar interações de mutualismo entre plantas e ácaros (ROMERO et al., 2011). Pesquisas têm enfatizado a inexistência de uma função fisiológica clara para essas estruturas. Entretanto, há uma forte associação entre ácaros e domácias, ou seja, que há uma relação positiva entre a presença de domácias e um grande número de ácaros, principalmente predadores (O'DOWD, 1994; GROSTAL; O'DOWD, 1994; MATOS et al., 2004).

A primeira citação de ácaros em domácias, no Brasil, foi feita no final do século XIX, por GÖLDI (1892) em cafeeiros no Rio de Janeiro. Em seu relatório, Göldi fez o seguinte comentário: "Não tardei a ver que se tratava de um pequeno acaridio, que faz das saliências logar de deposito para sua progenitura. O bello acaridio, segundo a minha determinação preliminar, está próximo do gênero Tetranychus (Figura 7), pertencendo em todo o caso ao grupo dos Trombididae. Diversos exemplares, acompanhados das necessárias indicações, foram remettidos a especialistas europeus, para estudos systematicos mais detalhados."

BITANCOURT $(1927,1935)$ também mencionou a ocorrência de ácaros no interior das domácias. Em seu trabalho, ele comentou o seguinte: "Praticando cortes tangenciaes na superfície inferior da folha, de modo a descobrir a cavidade das pequenas cryptas, encontram-se quase sempre pequenos acaros ou seus vestígios. Os adultos são raramente encontrados. A Figura 8 representa um dos acaros encontrados, sendo possível, entretanto, que existam várias espécies nas cryptas das folhas do cafeeiro. Para a devida identificação do pequeno arachnideo, teciono enviar as minhas preparações a um especialista".

No interior das domácias é possível encontrar ovos, exúvias e em geral indivíduos em diferentes fases de desenvolvimento (GÖLDI, 1892; BITANCOURT, 1927, 1935; MINEIRO, 2006). De qualquer modo, essas estruturas costumam ser visitadas ou habitadas por ácaros. $A$ acarofauna em cafeeiro é muito complexa e a composição das espécies, principalmente de predadores, pode variar bastante de uma cultivar para outra (MINEIRO et al., 2006b).

Existem diferenças naca composição acarina entre cultivares de cafeeiro. As diferenças nas características de cada espécie de cafeeiro e de seus respectivos cultivares podem influenciar aas comunidades de ácaros, variável em função 
da disponibilidade de presas específicas e/ou alternativas, além da arquitetura da planta e composição química das plantas de café.

\section{Fungos, algas e bactérias}

NAKAMURA et al. (1992) encontraram bactérias, fungos e algas azuis em domácias. Porém nesse estudo não foram relatadas as espécies encontradas.

Hirsutella sp. É um dos mais importantes patógenos que ocorrem em populações de ácaros no Brasil, sendo o primeiro relato desse fungo obtido em ácaros de cafeeiros nos municípios de Jeriquara e Garça (SP). As espécies de ácaros encontradas infectadas no interior de domácias foram Brachytydeus sp. (Figura 9A e 9B) (Tydeidae) e Homeopronematus sp. (Iolinidae), além de Stigmaeidae (Figura 9C) e Phytoseiidae (Figura 9D) (MINEIRO et al., 2003).

\section{Lecanicillium muscarium (Petch)} Zare \& Gams. Esse fungo foi encontrado infectando ácaros no interior de domácias (Figura 10). As espécies de ácaros encontradas infectadas foram Brachytydeus sp. e Homeopronematus sp. (MINEIRO et al., 2004). Testes de patogenicidade desse fungo na forma de conídios e blastosporos em adultos de Tetranychus urticae Koch (Tetrany- chidae) mostraram que os blastoporos proporcionaram mortalidades entre 44 a 72\% (LEITE et al., 2004). A câmara das domácias pode facilitar a infecção por entomopatógenos.

\section{Considerações finais}

A associação entre plantas com domácias e ácaros é um bom exemplo de como as características específicas das folhas da planta e esses organismos podem interagir um sobre o outro. Contudo, ao se avaliar diferentes espécies de Coffea com domácias e a relação entre essas estruturas e os ácaros, também há necessidade de se levar em consideração que outros fatores, além dessas estruturas, podem influenciar a distribuição dos ácaros nas folhas, como: os aspectos nutricionais da planta, o vigor e a conformação das plantas, a disponibilidade de presas para os predadores e os aspectos químicos das folhas.

Estudos voltados para o entendimento das interações existentes entre ácaros predadores e essas estruturas são de grande importância, uma vez que podem auxiliar em programas de manejo integrado. A presença de domácias em cafeeiros pode contribuir para um melhor desempenho de ácaros predadores e até mesmo de fungívoros como agentes de controle biológico, uma vez que, essas estruturas favorecem a permanência desses organismos nas plantas. 


\section{Agradecimentos}

À FAPESP pelo apoio a essa pesquisa (Processes \# 2017/50334-3 e 2016/069194) e a Embrapa-Café (Consórcio Pesquisa Café) pela bolsa ao primeiro autor; ao CNPq pela bolsa de produtividade aos segundo e terceiro autores. Aos pesquisadores do Centro de Pesquisa do Café do Instituto Agronômico de Campinas que gentilmente cederam materiais para a realização das fotos de domácias.

\section{Referências}

ADÂMOLI DE BARROS, M.A. Morfologia e anatomia das domácias em Coffea arabica L. Anais da Escola Superior de Agricultura “Luiz de Queiroz”, v.17, p. 165-206, 1961.

ADÂMOLI DE BARROS, M.A. Estudo comparativo das domácias de folhas normais e domácias de folhas cujas plantas foram cultivadas com deficiências e excessos de micronutrientes ( $\mathrm{Fe}, \mathrm{Mn}$, Mo e Cu) em Coffea arabica L. variedade caturra K.M.C. Anais da Escola Superior de Agricultura "Luiz de Queiroz", v. 20, p.229-240, 1963.

AGRAWAL, A.A.; KARBAN, R. Domatia mediate plant-arthropod mutualism. Nature, v. 387, p. 562563, 1997.

BITANCOURT, A.A. A acarophilia do cafeeiro e seu papel eventual na defesa da planta contra os fungos parasitas. Boletim Biológico, v. 10, p. 203-208, 1927.

BITANCOURT, A.A. Os "acarodomacios" da folha do cafeeiro. Revista do Instituto de Café do Estado de São Paulo, v. 10, n. 106, p. 2304-2307, 1935.

BITANCOURT, A.A. A mancha anular do cafeeiro, uma nova doença do cafeeiro. O Biológico, v. 4 , p. 404-405, 1938.

CHEVALIER, A. Les caféiers du globe. Fascicule III. Sistématique des caféiers et fauxcaféiers maladies et insects nuisibles. Paris: Paul Lechevalier, 1947. 356 p.

DEDECCA, D.M. Anatomia e desenvolvimento ontogenético de Coffea arabica L. var. Typica Cramer. Bragantia, v.16, p. 315-367, 1957.

GERSON, U. Pest control by mites (Acari): present and future. Acarologia, v.54, n.4, p. 371-394, 2014.

GERSON, U.; SMILEY, R.L.; OCHOA, R. Mites (Acari) for pest control. Oxford: Blackwell Science, 2003. $539 \mathrm{p}$.

GÖLDI, E.A. Relatório sobre a molestia do cafeeiro na província do Rio de Janeiro. Archivos do Museu Nacional do Rio de Janeiro, v. 8, n. 2, p.7-124, 1892.

GROSTAL, P.; O'DOWD, D.J. Plants, mites and mutualism: leaf domatia and the abundance and reproduction of mites on Viburnum tinus (Capriofoliaceae). Oecologia, v. 97, p. 308-315, 1994.

HOY, M.A. Agricultural Acarology - Introduction to integrated mite management. CRC Press. Taylor \& Francis Group. 2011. 410p.

LEITE, L.G.; ZENI, G.F.M.; MINEIRO, J.L.C.; RAGA, A.; HUMBER, R.A. \& TAVARES, F.M. Virulência de Lecanicillium muscarium na forma de conídio e blastosporo contra o ácaro rajado, Tetranychus urticae. Arquivos do Instituto Biológico, 71 (suplemento). 2004. 
LUNDSTRÖEM, A.N. Pflanzenbiologische studien II. Die Anpassungen der Pflanzenan Thiere. Domatienführende Pflanzen. In: MARIANI, M.J. Les caféiers. Paris: L' Université, 1887. p.1-88.

MATOS, C.H.C.; PALLINI, A.; CHAVES, F.F.; GALBIATI, C. Domácias do cafeeiro beneficiam o ácaro predador Iphiseiodes zuluagai Denmark \& Muma (Acari: Phytoseiidae)?. Neotropical Entomology, v. 33, n. 1, p. 57-63, 2004.

MATOS, C.H.C.; PALLINI, A.; BELLINI, L.L.; FREITAS, R.C.P. Domácias e seu papel na defesa das plantas. Ciência Rural, v. 36, n. 3, p. 1021 - 1026, 2006.

McMURTRY, J.A.; CROFT, B.A. Life-styles of phytoseiid mites and their roles in biological control. Annual Review of Entomology, v. 42, p. 291-321, 1997.

MINEIRO, J.L.C. Ecologia do ácaro da mancha-anular (Brevipalpus phoenicis (Geijskes)) (Acari: Tenuipalpidae) em cafeeiros no Estado de São Paulo. 179p. Tese de Doutorado. Centro de Energia Nuclear na Agricultura, Universidade de São Paulo. 2006. 179p.

MINEIRO, J.L.C.; ARTHUR, V.; RAGA, A.; SATO, M.E; LEITE, L.G. \& MORAES, G.J. de. Primeiro relato de Hirsutella sp. Sobre ácaros do cafeeiro, no Brasil. In: VIII Simpósio de Controle Biológico - SICONBIOL. São Pedro, SP. Resumos... 2003.

MINEIRO, J.L.C.; RAGA, A.; LEITE, L.G.; HUMBER, R.A.; SATO, M.E. \& NICASTRO, R.L. In: XX Congresso Brasileiro de Entomologia. Gramado, RS. Resumos... Pág. 175. 2004.

MINEIRO, J.L.C.; SATO, M.E.; RAGA, A.; ARTHUR, V.; MORAES, G.J. de; SARRETA, F.O.; CARRIJO, A. Diversidade de ácaros (Arachnida: Acari) em Coffea arabica L. cv. Mundo Novo, nos municípios de Jeriquara e Garça, Estado de São Paulo. Biota Neotropica, v.6, n.2., p.1-15, $2006 a$.

MINEIRO, J.L.C.; SATO, M.E; RAGA, A.; ARTHUR, V. Population dynamics of phytophagous and predaceous mites on coffee in Brazil, with emphasis on Brevipalpus phoenicis (Acari: Tenuipalpidae). Experimental and Applied Acarolology, v. 44, p.277-291, 2008.

MINEIRO, J.L.C.; SATO, M.E; RAGA, A.; ARTHUR, V.; CANGANI, K.G.; BARBOSA, F.V. Diversidade de ácaros (Arachnida: Acari) em cinco cultivares de duas espécies de cafeeiros (Coffea spp.) em Garça, estado de São Paulo. Arquivos do Instituto Biológico, v.73, n.3, p. 333 - 341, 2006b.

NAKAMURA, T.; TANICUGHI, T.; MAEDA, E. Leaf anatomy of Coffea arabica L. with reference to domatia. Japanese Journal of Crop Science, v.61, p.642-650, 1992.

NORTON, A.P.; ENGLISH-LOEB, G.; GADOURY, D.; SEEM, R.C. Mycophagous mite and foliar pathogens: leaf domatia mediate tritrophic interactions in grapes. Ecology, v. 81, p. 490-449, 2000.

O'DOWD, D.J. Mite association with the leaf domatia of coffee (Coffea arabica) in north Queensland, Australia. Bulletin of Entomological Research, v. 84, p.361-366, 1994.

O'DOWD, D.J.; WILSON, M.F. Leaf domatia and mites on Australian plants: ecological and evolutionary implications. Biological Journal of the Linnean Society, v.37, p.191- 236, 1989.

PEMBERTON, R.W.; TURNER, C.E. Occurrence of predatory and fungivorous mites in leaf domatia. American Journal of Botany, v. 76, n. 1, p. 105-112, 1989.

RAGA, A.; MINEIRO, J.L.C.; WOLFF, V.R.S. Novos registros de hospedeiros de cochonilhas (Hemiptera: Diaspididae, Coccidae) no Estado de São Paulo. In: XVI Reunião Anual do Instituto Biológico, 2003, São Paulo. Arquivos do Instituto Biológico, 2003. v.70.

REIS, P.R.; ZACARIAS, M.S. Ácaros em cafeeiro. EPAMIG. Boletim Técnico n 81. 2007. 76p.

ROMERO, G.Q.; BENSON, W.W. Leaf domatia mediate mutualism between mites and a tropical tree. Oecologia, v. 140, p. 609-616, 2004. 
ROMERO, G.Q.; BENSON, W.W. Biotic interactions of mites, plants and leaf domatia. Current Opinion in Plant Biology, v. 8, p. 436-440, 2005.

ROMERO, G.Q.; DAUD, R.D.; SALOMÃO, A.T.; MARTINS, L.F.; FERES, R.J.F.; BENSON, W.W. Mites and leaf domatia: no evidence of mutualism in Coffea arabica plants. Biota Neotropica, v. 11, n. 1, p. 27-34, 2011.

ROZARIO, S.A. Association between mites and leaf domatia: evidence from Bagladesh, South Asia. Journal of Tropical Ecology, v. 11, p. 99-108, 1995.

VEGA, F.E.; OCHOA, R.; ASTORGA, C. \& WALTER, D.E. Mites (Arachnida: Acari) inhabiting coffee domatia: a short review and recent findings from Costa Rica. International Journal of Acarology, v.33, n. 4, p. 291-295, 2007.

WALTER, D.E. Living on leaves: mites, tomenta, and leaf domatia. Annual Review of Entomology, v. 41, p. 101-114, 1996.

WALTER, D.E.; O'DOWD, D.J. Leaves with domatia have more mites. Ecology, v. 73, p. 15141518, 1992.

WALTER, D.E.; PROCTOR, H.C. Mites: ecology, evolution and behavior. Wallingford, Oxon, UK: CAB International. 1999. 322p.

WRIGLEY, G. Coffee. New York: Longman Scientific \& Technical. John Wiley, 1988. 403p.

Tabela 1. Número de domácias avaliadas, média por folhas e porcentagem de folhas sem domácias.

\begin{tabular}{lccc}
\hline & Total avaliado & Média por folha & Folhas sem domácias \\
\hline Coffea canephora cv. Apoatã & 25.987 & 8 & $10 \%$ do total \\
C. arabica cv. Mundo Novo & 140.140 & 11 & $0,5 \%$ do total \\
C. arabica cv. Icatu Vermelho & 32.307 & 10 & $0,8 \%$ do total \\
C. arabica cv. Icatu Amarelo & 37.354 & 12 & $0,4 \%$ do total \\
C. arabica cv. Catuaí Amarelo & 30.621 & 10 & $1,7 \%$ do total \\
\hline
\end{tabular}


Tabela 2. Espécies de ácaros encontradas no interior de domácias em cafeeiros no Estado de São Paulo.

\begin{tabular}{|c|c|c|c|c|c|c|c|c|}
\hline \multirow[t]{3}{*}{ Ácaros } & \multirow{3}{*}{$\begin{array}{c}\text { Jeriquara* }^{*} \\
\text { Coffea arabica } \\
\text { Mundo Novo }\end{array}$} & \multicolumn{5}{|c|}{ Garça* } & \multirow{3}{*}{$\begin{array}{l}\text { Atibaia } \\
\text { Coffea arabica } \\
\text { Mundo Novo }\end{array}$} & \multirow{3}{*}{$\begin{array}{c}\text { Campinas } \\
\text { Coffea arabica } \\
\text { Mundo Novo }\end{array}$} \\
\hline & & \multicolumn{4}{|c|}{ Coffea arabica } & \multirow{2}{*}{$\begin{array}{c}\begin{array}{c}\text { Coffea } \\
\text { canephora }\end{array} \\
\text { Apoatã }\end{array}$} & & \\
\hline & & Mundo Novo & Icatu Amarelo & Icatu vermelho & Catuaí Amarelo & & & \\
\hline \multicolumn{9}{|l|}{ MESOSTIGMATA } \\
\hline \multicolumn{9}{|l|}{ Amersoiidae } \\
\hline sp. & & & & & & $\mathrm{X}$ & & \\
\hline \multicolumn{9}{|l|}{ Phytoseiidae } \\
\hline Amblyseius aerialis & $\mathrm{x}$ & & & & & & & \\
\hline Amblyseius compositus & & & & & & & $\mathrm{x}$ & \\
\hline \multicolumn{9}{|l|}{ Euseius alatus } \\
\hline Euseius citrifolius & $\mathrm{x}$ & $x$ & $\mathrm{X}$ & & & & & \\
\hline Euseius concordis & $\mathrm{x}$ & $\mathrm{X}$ & $x$ & & & $\mathrm{X}$ & $x$ & \\
\hline \multicolumn{9}{|l|}{ ORIBATIDA } \\
\hline \multicolumn{9}{|l|}{ Grupo Astigmatina } \\
\hline \multicolumn{9}{|l|}{ Acaridae } \\
\hline Tyrophagus sp. & & & & $x$ & & $x$ & & \\
\hline \multicolumn{9}{|l|}{ Winterschmidtiidae } \\
\hline Czenspinskia sp. & & & & & & & $x$ & \\
\hline Oulenzia sp. & & & & & & & & $x$ \\
\hline Saproglyphus sp. & $\mathrm{x}$ & & $x$ & $x$ & & $\mathrm{x}$ & & \\
\hline \multicolumn{9}{|l|}{ PROSTIGMATA } \\
\hline \multicolumn{9}{|l|}{ Bdellidae } \\
\hline Bdella sp. & $x$ & $x$ & & & $x$ & & & \\
\hline Spinibdella sp. & $x$ & & & & & & & \\
\hline Tetrabdella sp. & & & & & & & & $x$ \\
\hline \multicolumn{9}{|l|}{ Cheyletidae } \\
\hline Hemicheyletia sp. & & & & & & & & $x$ \\
\hline Prosocheyla sp. & & & & & & & $x$ & \\
\hline \multicolumn{9}{|l|}{ Iolinidae } \\
\hline Homeopronematus sp. & $x$ & $x$ & $x$ & $x$ & $x$ & & & \\
\hline Parapronematus acaciae & & & & $x$ & $x$ & & & \\
\hline \multicolumn{9}{|l|}{ Meyerellidae } \\
\hline Triophtydeus sp. & $x$ & & & & & & & \\
\hline \multicolumn{9}{|l|}{ Stigmaeidae } \\
\hline Agistemus brasiliensis & $x$ & $x$ & & $x$ & $x$ & $x$ & & \\
\hline Zetzellia malvinae & $x$ & $x$ & $x$ & $x$ & $x$ & $x$ & $x$ & $x$ \\
\hline Tarsonemidae & & & & & & & & \\
\hline Daidalotarsonemus sp. & & & & $x$ & & & & \\
\hline Fungitarsonemus sp. & & & & & & & & \\
\hline Tarsonemus sp. & $x$ & $x$ & $x$ & $x$ & & & & \\
\hline Tenuipalpidae & & & & & & & & \\
\hline Brevipalpus sp. & $x$ & $x$ & $x$ & $x$ & & $x$ & & \\
\hline Tetranychidae & & & & & & & & \\
\hline Oligonychus ilicis & & & $x$ & & & & & \\
\hline Tydeidae & & & & & & & & \\
\hline Brachytydeus formosa & $x$ & $x$ & $x$ & $x$ & $x$ & $x$ & $x$ & \\
\hline Brachytydeus sp.1 & $x$ & $x$ & $x$ & $x$ & $x$ & $x$ & $x$ & $x$ \\
\hline Brachytydeus sp.2 & & $x$ & & & & & & \\
\hline
\end{tabular}

*Fonte: MINEIRO et al. (2006a, 2006b). 


\section{Lista das figuras}

Figura 1. Domácias de Coffea arabica: (A) arredondada e (B) alongada.
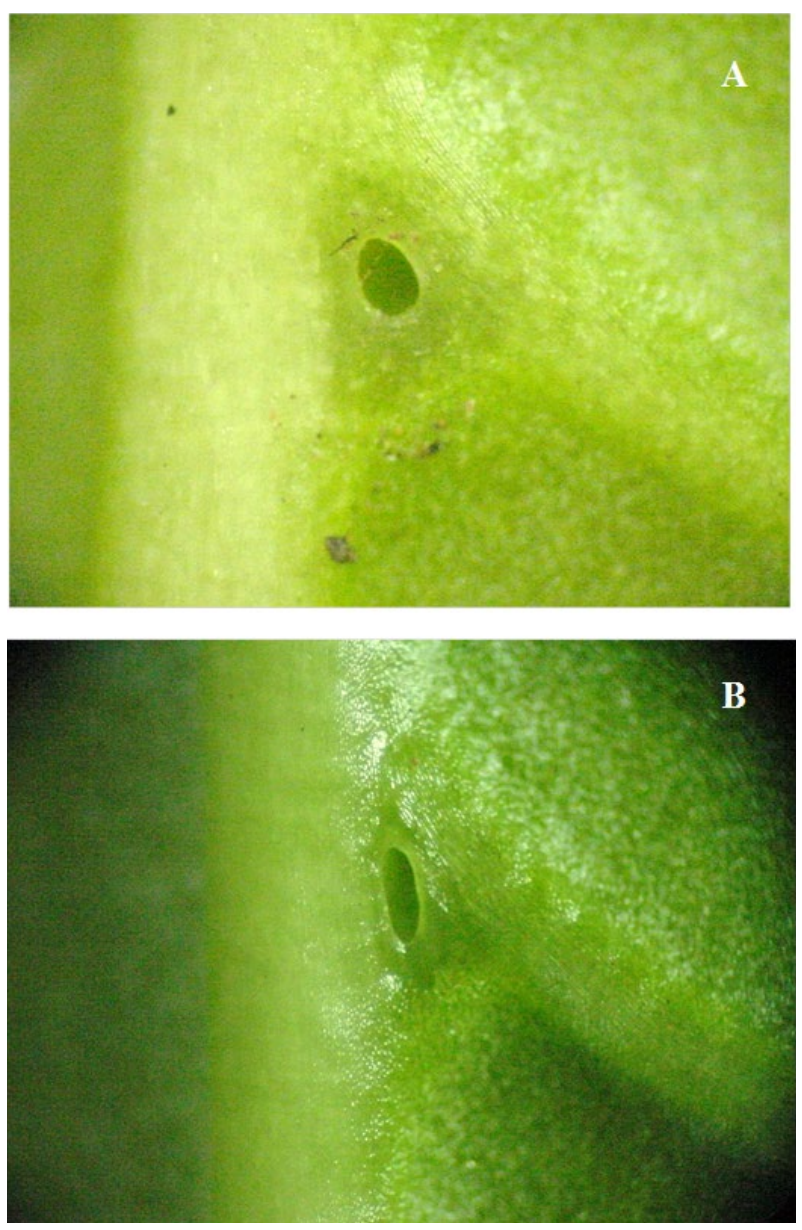

Figura 2. Detalhe domácia de Coffea canephora.

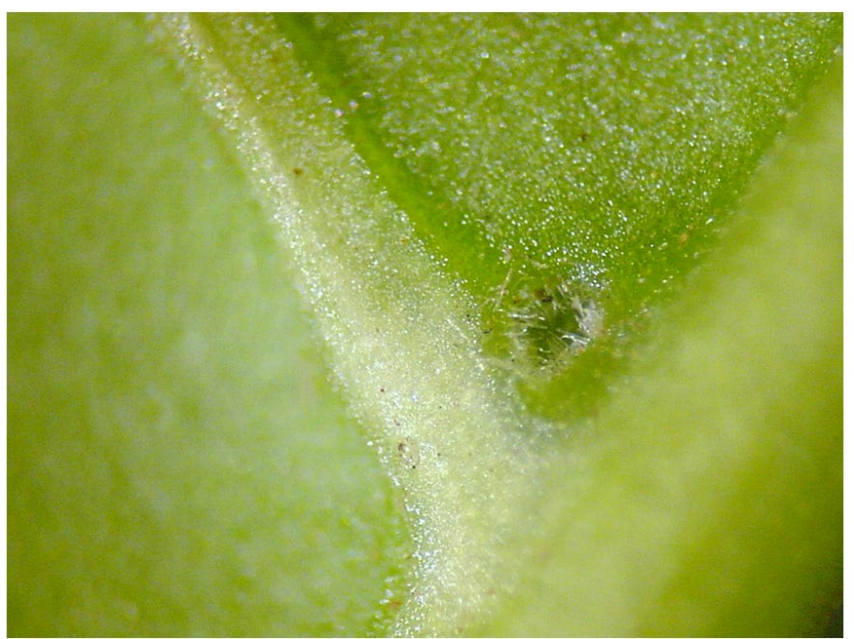


Figura 3. Domácia de Coffea racemosa, (A) ácaro Phytoseiidae no interior, (B) ovos de ácaros.
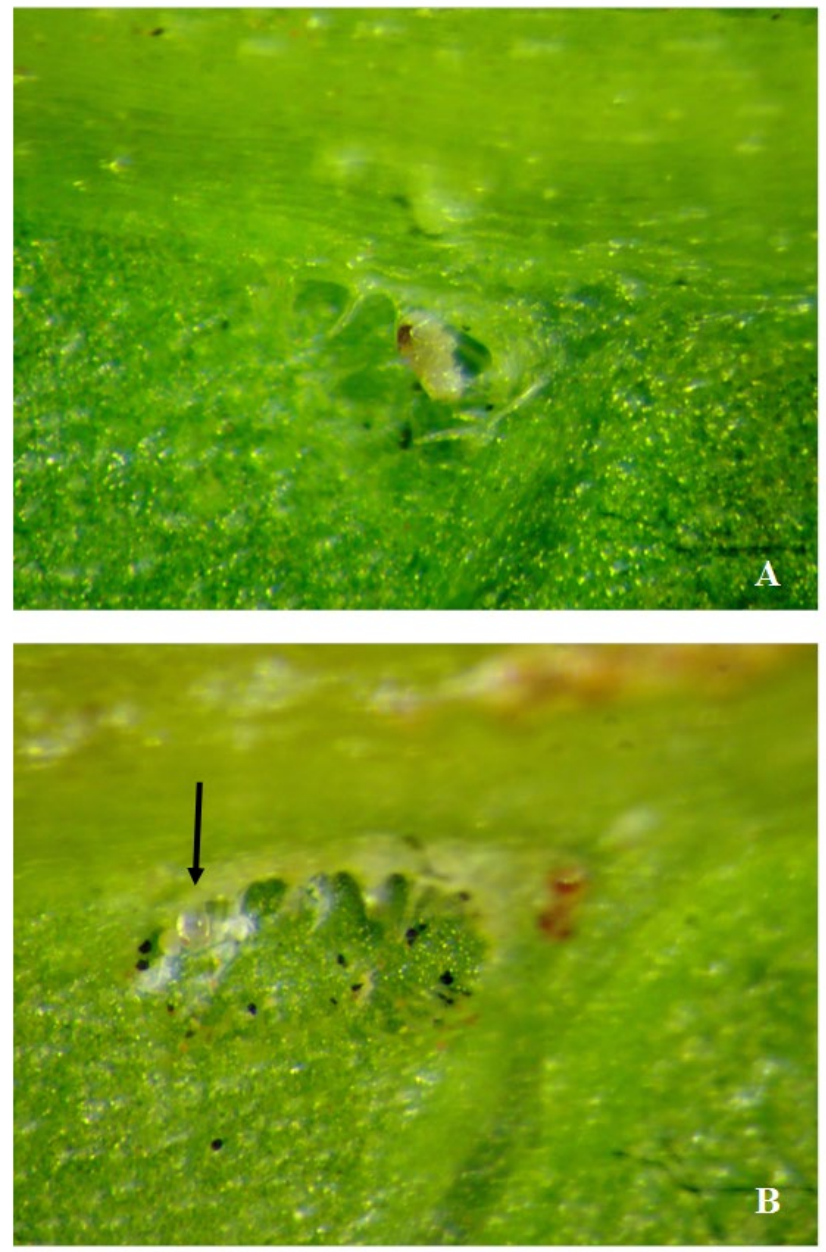

Figura 4. Domácia de Coffea salvatrix, com ácaro tideídeo, ovos e exúvias.

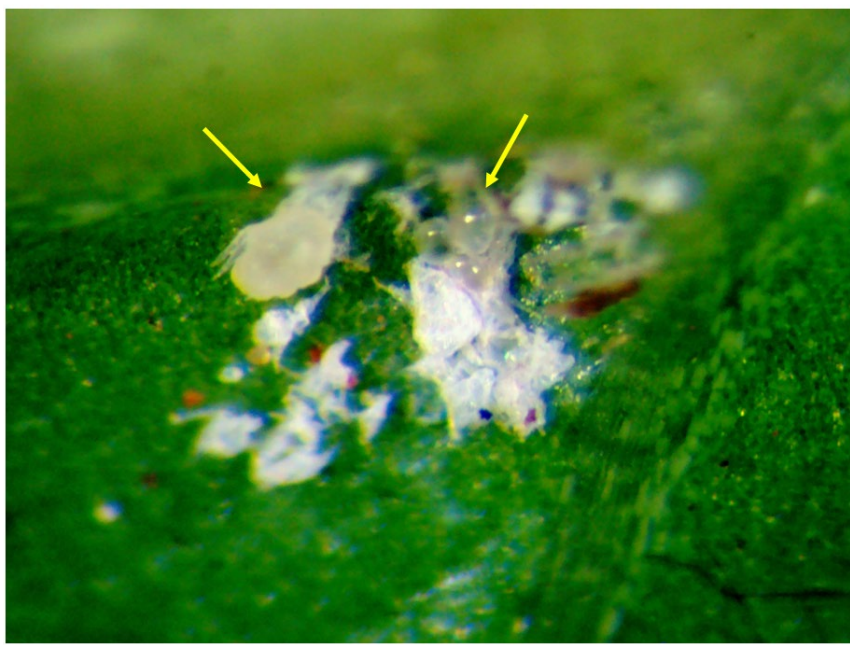


Figura 5. Detalhe de domácia de Coffea stenophylla.

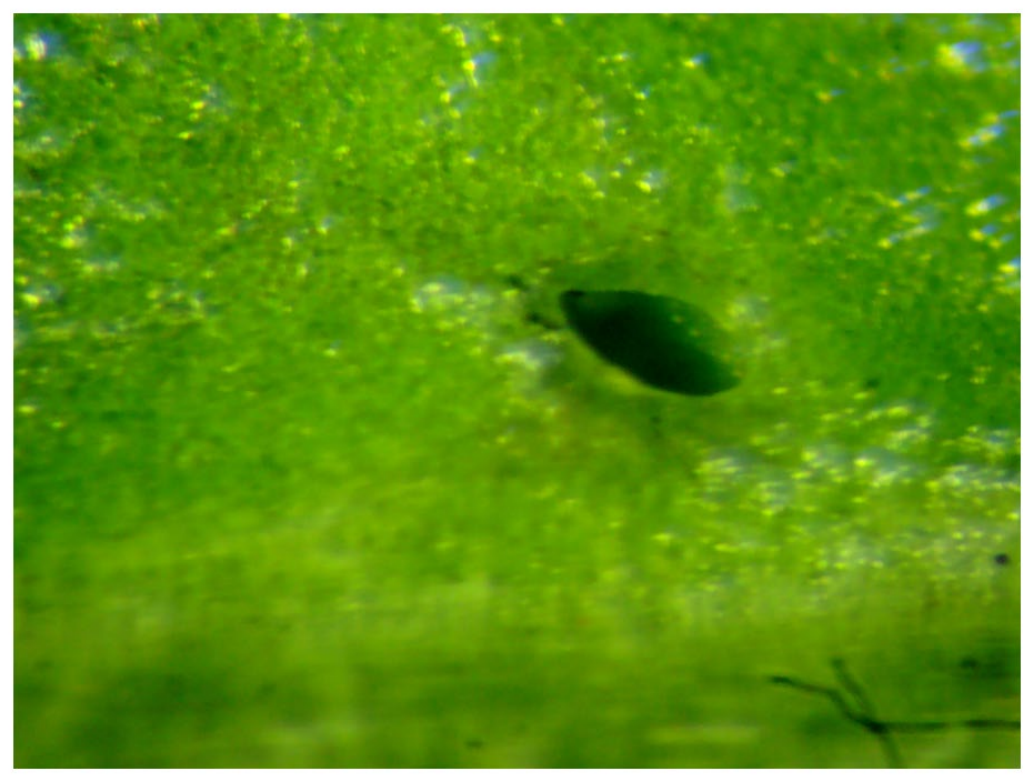

Figura 6. Domácias em Coffea canephora cv. Guarini (A). Detalhe domácias na nervura secundária (B) e domácias na nervura principal (C).

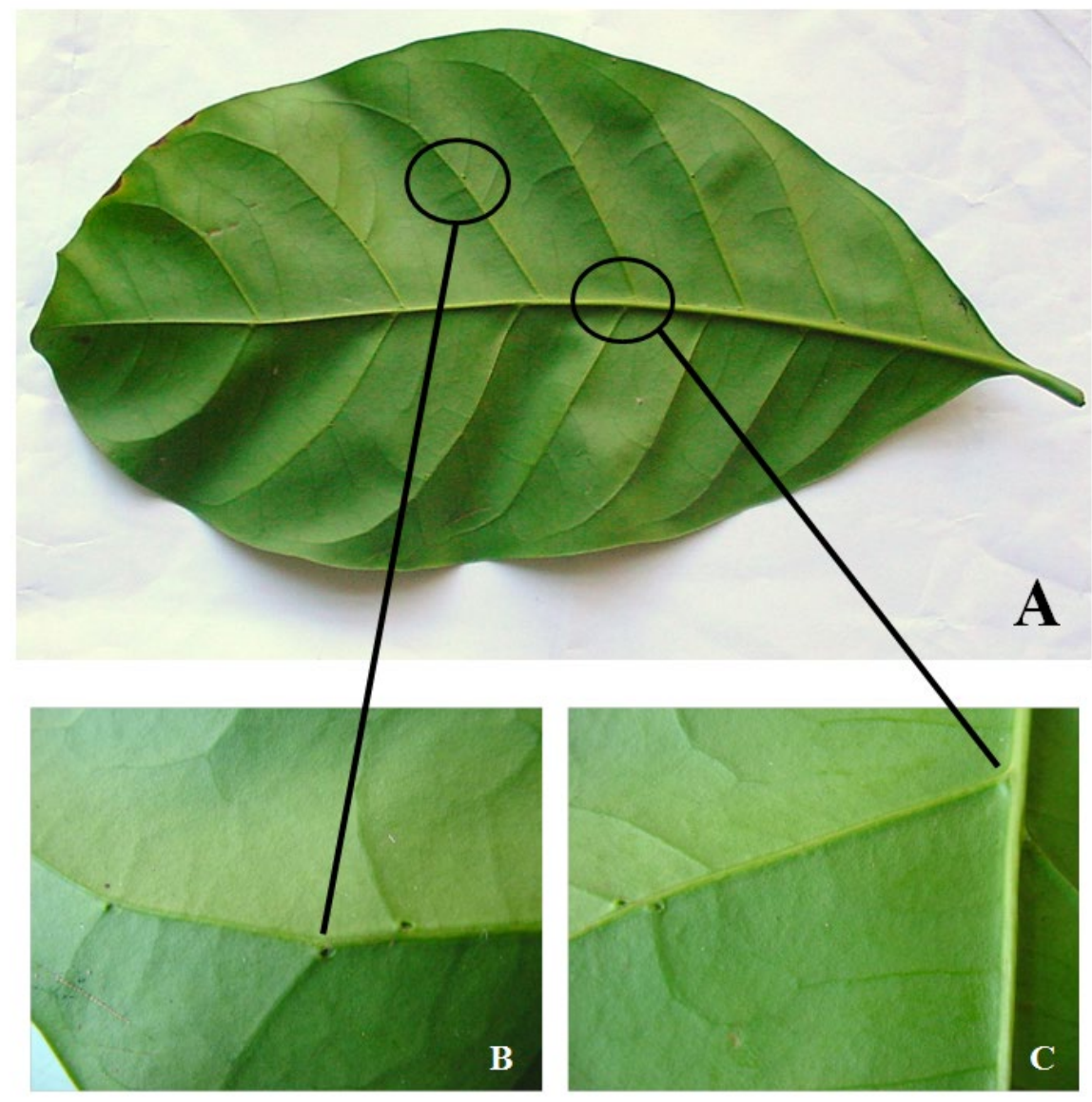


Figura 7. Ácaro encontrado por Göldi no interior de domácia de cafeeiro no estado do Rio de Janeiro (Adaptado de Göldi, 1892).

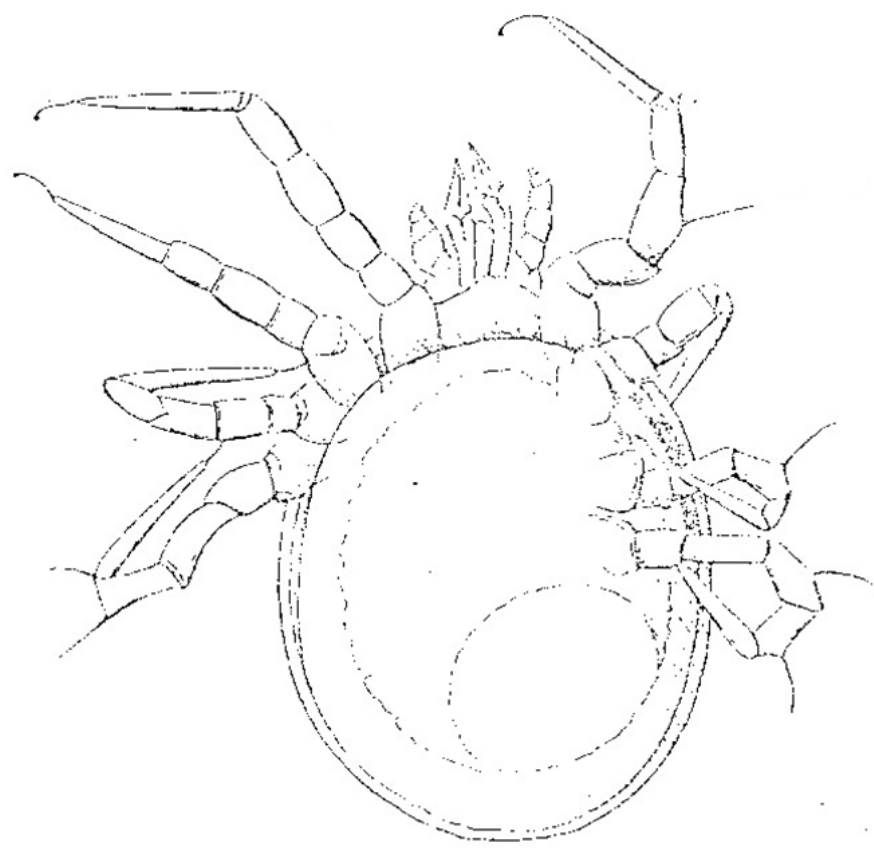

Figura 8. Ácaro encontrado por A. A. Bitancourt no interior de domácia de cafeeiro no Estado de São Paulo (Adaptado de Bitancourt, 1927).

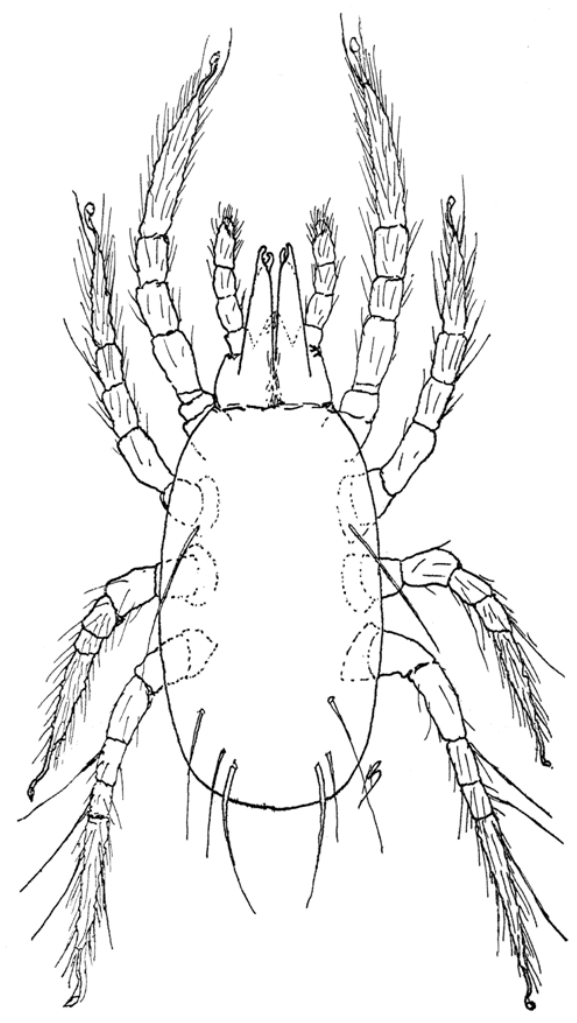


Figura 9. Ácaros infectados por Hirsutella sp. no interior de domácias, A e B - Tydeidae, C- Stigmaeidae, D - Phytoseiidae.
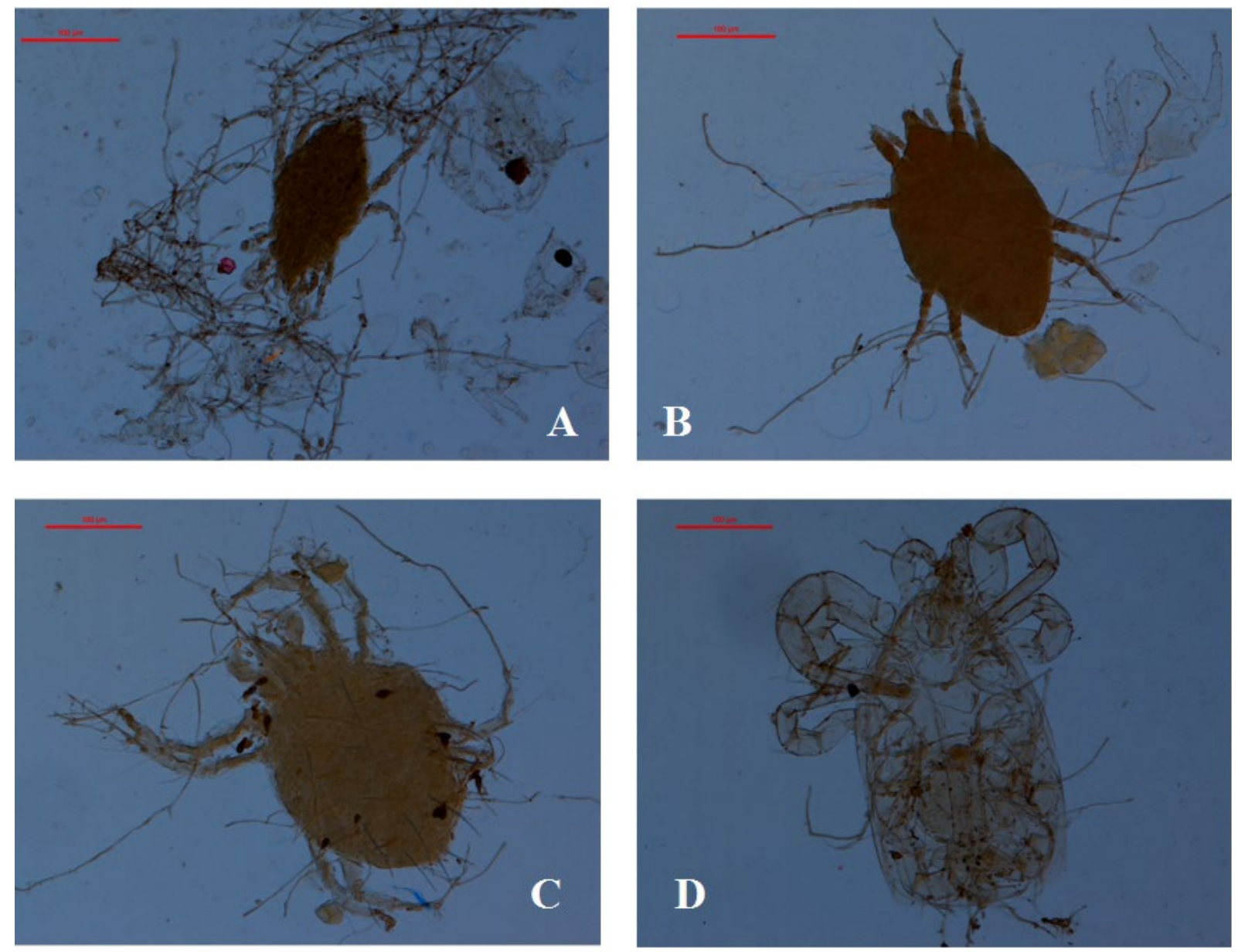

Figura 10. Detalhe do fungo Lecanicillium muscarium na domácia de cafeeiro.

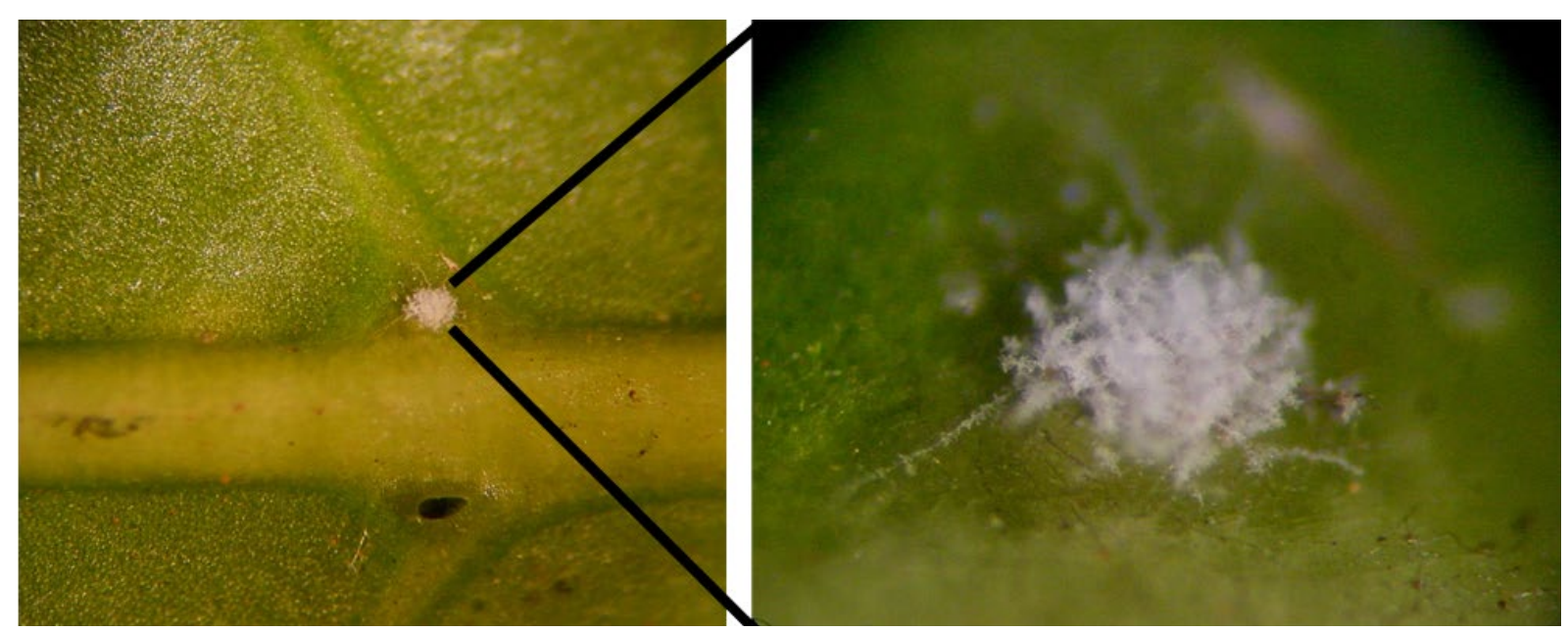

Recebido em: 16/04/2019

Aprovado em: 15/08/2019 